\title{
Psychological Factors Related to Eating Disordered Behaviors: A Study with Portuguese Athletes
}

\author{
Luiz Silva, A. Rui Gomes, and Carla Martins \\ Universidade do Minho (Portugal)
}

\begin{abstract}
This study analyzes eating disordered behaviors in a sample of Portuguese athletes and explores its relationship with some psychological dimensions. Two hundred and ninety nine athletes (153 male, 51.2\%) practicing collective (65.2\%) or individual sports (34.8\%) were included. The assessment protocol included the Eating Disorder Examination Questionnaire (EDE-Q) (Fairburn \& Beglin, 1994); the Sport Condition Questionnaire (Bruin et al., 2007; Hall et al., 2007); the Sport Anxiety Scale (Smith et al., 2006); the Task and Ego Orientation in Sport Questionnaire (Duda, 1992; Duda \& Whitehead, 1998); the Cognitive Evaluation of Sport-Threat Perceptions (Cruz, 1994; Lazarus, 1991); and the Self-Presentation Exercise Questionnaire (Gammage et al., 2004). Results revealed that: i) no case of clinical significance was detected in the four dimensions of the EDE-Q simultaneously; ii) females scored higher on the EDE-Q Global Score, and athletes with the better sport results scored higher on the Restraint subscale; iii) athletes with a higher desire to weigh less scored higher on the EDE-Q Global Score; iv) athletes with lower scores on EDE-Q displayed more positive results on the psychological measures; v) several psychological dimensions were identified as predictors of eating disordered behaviors. In conclusion, the prevalence of eating disordered behaviors was negligible in this study, yet the relationship of this problem with personal, sport and psychological factors was evident.
\end{abstract}

Keywords: eating disorders, eating behaviors, sport psychology.

Este estudio analiza los trastornos alimentarios en una muestra de atletas portugueses y explora la relación de este problema con algunas dimensiones psicológicas. Participaron en el estudio 299 atletas (153 hombres, 51.2\%), practicantes de modalidades colectivas (65.2\%) e individuales (34.8\%). El protocolo de evaluación incluyó los siguientes instrumentos: Cuestionario de Evaluación de los Trastornos Alimentarios (CETA, Fairburn y Beglin, 1994); Cuestionario de Evaluación del Estado Físico y Deportivo (Bruin et al., 2007; Hall et al., 2007); Escala de Ansiedad en el Deporte-2 (Smith et al., 2006); Cuestionario de Orientación Motivacional para el Deporte (Duda, 1992; Duda y Whitehead, 1998); Escala de Evaluación Cognitiva de la Competencia: Percepción de Amenaza (Cruz, 1994; Lazarus, 1991); y el Cuestionario de Auto-presentación en el Deporte (Gammage et al., 2004). Los resultados revelaron: i) inexistencia de valores con significación clínica en las dimensiones evaluadas simultáneamente en el CETA; ii) las mujeres presentaron valores superiores en la dimensión global del CETA y los atletas con mejores resultados deportivos asumieron una mayor tendencia para la restricción en el CETA; iii) atletas con el deseo de pesar menos obtuvieron resultados más elevados en el valor global del CETA; iv) atletas con valores inferiores en el CETA total mostraron resultados más positivos en las dimensiones psicológicas; v) diferentes dimensiones psicológicas fueron identificadas como predictoras de los trastornos alimentarios. En conclusión, y a pesar de que la prevalencia de trastornos alimentarios no fue significativa en este estudio, los resultados relativos a la relación con los factores personales, deportivos y psicológicos fueron muy evidentes.

Palabras clave: trastornos alimentarios, alimentación, psicología del deporte.

Correspondence concerning this article should be addressed to A. Rui Gomes. Escola de Psicologia. Universidade do Minho. Campus de Gualtar. 4710-057 Braga. (Portugal). Phone: +253604232. Fax: +253604224. E-mail: rgomes@psi.uminho.pt 
The study of the consequences of sport in athletes' development has been a major topic of research within the sport sciences' literature. In general, there is sufficient evidence to sustain the positive effects of sport in the physical and psychological condition of athletes, improving their health and feelings of well-being (Biddle \& Mutrie, 2001; Buckworth \& Dishman, 2002). Conversely, less attention has been given to the possible adverse outcomes of sport practice, especially when athletes' investment and dedication becomes excessive (Szabo, Frenkl, \& Caputo, 1997). This is even more disturbing if we consider the evidence that certain psychological patterns can lead to negative physical and mental states (e.g., obsessive attitudes towards exercising, excessive exercising, etc.) (Bamber, Cockerill, Rodgers, \& Carroll, 2003; Hausenblas \& Symons, 2002).

One indicator of these negative states is related to eating disordered behaviors, leading to the question whether sport practice can increase the risk of developing eating disorders. This relationship seems to be associated with some psychological and social factors, such as the tendency for perfectionism and drive for achievement (Haase, Prapavessis, \& Owens, 2002; Johnson, 1994), the idealization of a fit and lean body (Muscat \& Long, 2008), the competitive demands of success (Fulkerson, Keel, Leon, \& Dorr, 1999) and the coach's pressure for excellence and fitness (Petrie, 1996).

Despite this multitude of aspects that can potentially trigger eating disordered behaviors, there is still little consensus about whether sport represents a factor that could promote these problems. For instance, along with studies showing the positive relationship between sport and the incidence of eating disorders in athletes (Byrne \& McLean, 2002; Davis \& Cowles, 1989; Hulley \& Hill, 2001; Sundgot-Borgen, 1993, 1994a, 1996), there are others that suggest the absence or insignificance of this relationship (Ashley, Smith, Robinson, \& Richardson, 1996; Harris \& Greco, 1990; Johnson, Powers, \& Dick, 1999), and even others that suggest the possibility of sport representing a protective factor for the occurrence of eating disorders (DiBartolo \& Shaffer, 2002; Hausenblas \& McNally, 2004). In a review of these researches, Byrne and McLean (2001) point out that the majority of studies draw attention to the absence of differences between athletes and non-athletes on the prevalence of eating disorders. However, they argue that this could be due to problems related to the size of the samples investigated, the use of inadequate procedures of analysis, the variety of diagnostic criteria applied to determine eating disorders, and even to the diversity of athletes that have been assessed.

Because of these difficulties, some authors have been highlighting the need to focus on other areas of study. Thus Petrie and Greenleaf (2007) stressed that the investigations need to abandon this comparative tendency, and instead becoming more useful by analyzing the psychological factors associated with eating disorders in athletes, as these factors may well represent potential risks to the development of such problems. For example, very few studies have tried to determine if sport anxiety can be a risk factor for eating disorders (Holm-Denoma, Scaringi, Gordon, Van Orden, \& Joiner, 2009). Likewise, it becomes essential to understand if there are some specific characteristics in the context of sport activity that could lead to this condition. At this level, the results on the differences between distinct kinds of sport and competitive levels are as scarce as inconsistent (Stoutjesdyk \& Jevne, 1993).

Therefore, the purpose of the present study is to contribute for the understanding of eating disordered behaviors in sport, examining the potential importance of some psychological dimensions (e.g., satisfaction with body shape and physical appearance, trait anxiety, motivational orientation, threat perception, and self-presentation processes) and relational factors (e.g., pressure from coaches regarding athletes controlling their weight) in the explanation of this problem. The choice of these variables was based not only on their importance in sport psychology, but also because they represent domains insufficiently analyzed in the explanation of eating disordered behaviors.

Thus this study analyses the prevalence of eating disordered behaviors in sport, taking into consideration some personal, sporting and psychological variables in the explanation of this phenomenon. More specifically, it sought to achieve the following goals:

i) To assess eating disordered behaviors in a sample of Portuguese athletes practicing collective and individual sports;

ii) To analyze the differences in eating disordered behaviors according to personal and sport characteristics of athletes;

iii) To examine the psychological differences between athletes according their tendency to eating disordered;

iv) To explore the psychological factors that could predict eating disordered behaviors.

\section{Method}

\section{Participants}

Two hundred and ninety nine athletes (146 females, $48.8 \% ; 153$ males, $51.2 \%)$ aged 14 to 39 years $(M=18.2$; $S D=4.3$ ) were recruited for this study. The majority of athletes practiced collective sports $(n=195,65.2 \%)$ in the following modalities: handball $(n=82,27.4 \%)$, volleyball $(n=59,19.7 \%)$ and basketball $(n=54,18.1 \%)$. The remaining 104 athletes $(34.8 \%)$ practiced individual sports, such as swimming $(n=36,12 \%)$, athletics $(n=30,10 \%)$, karate $(n=23,7.7 \%)$ and taekwondo $(n=15,5 \%)$. In what concerns the competitive level, there were three groups of athletes according to their stages of the sport career, namely 
the juvenile group ( $n=133,44.5 \%)$, junior group ( $n=90$, $30.1 \%)$, and the senior group $(n=76,25.4 \%)$. A significant number of athletes $(n=86,28.8 \%)$ had had already won a national title.

\section{Measures}

The assessment protocol included six instruments, all of them answered in a likert format. All instruments' reliability was tested using the Cronbach's alpha and their values are presented in the description of each one.

Eating Disorder Examination Questionnaire (EDE-Q; Fairburn \& Beglin, 1994, 2008; Portuguese translation by Machado, 2007). This instrument is a self-report version of the Eating Disorder Examination, a well-established investigator-based interview that evaluates attitudes and behaviors related with eating disorders. Is comprises 28 items answered on a seven-point Likert-scale ranging from 0 ("None") to 6 ("Every day"), and provides four subscales reflecting the severity of behaviors associated with eating disorders occurred in the past 28 days, namely: i) Restraint (five items; $\alpha=.76$ ): assesses behaviors related to the avoidance of food and the rules followed in diets and feeding (e.g., avoidance of eating); ii) Eating concern (five items; $\alpha=.69$ ): focuses on the fear of losing control over eating and apprehension about what to eat (e.g., eating in secret); iii) Shape concern (eight items; $\alpha=.90$ ): measures the feelings of dissatisfaction with own body shape, body exposure in public situations and emphasis on physical fitness (e.g., avoidance of exposure); and iv) Weight concern (four items; $\alpha=.82$ ): evaluates the feelings of dissatisfaction with the current weight and the need to maintain or achieve a certain body weight (e.g., desire to lose weight). Subscale scores were obtained by adding item scores and the sum was divided by the total number of items forming each one. The EDE-Q also included six items assessing specific behaviors related with eating disorders (e.g., "over the past 28 days, how often have you caused vomiting to control your weight or body shape?"). Excluding those six additional items, we calculated a score of the global scale which resulted from the average of the four subscale scores $(\alpha=.94)$. Finally, it should be mentioned that the scores of each subscale were used to identify problematic values, those equal to or greater than four, as this is the cut-off point for clinical significance adopted in other studies (Luce, Crowther, \& Polé, 2008; Mond, Hay, \& Owen, 2006).

Sport Condition Questionnaire (SCQ; Gomes, 2007 based on the works of Bruin, Oudejans, \& Bakker, 2007 and Hall, Kerr, Kozub, \& Finnie, 2007). For the purpose of this study we have used two dimensions: i) Satisfaction with body shape and physical appearance, that includes three items $(\alpha=.81)$ answered on a five-point Likert-scale, ranging from 1 ("Extremely dissatisfied") to 5 ("Extremely satisfied") (e.g., "I am satisfied with my weight"); and ii) Weight-related coach pressure, comprising four items $(\alpha=.81)$ answered on a five-point Likert-scale ranging from 1 ("Strongly disagree") to 5 ("Totally agree") (e.g., "My coach claims that it is urgent for me to diet"). Subscale scores were obtained by adding item scores and the sum was divided by the total number of items forming each subscale.

Sport Anxiety Scale (SAS-2; Smith, Smoll, Cumming, \& Grossbard, 2006; Portuguese adaptation by Cruz \& Gomes, 2007). The SAS-2 is a multidimensional measure of sport performance anxiety composed by 15 items answered on a four-point Likert-scale ranging from 1 ("Not at all") to 4 ("Very much"), which assesses both cognitive (in terms of worry and concentration disruption in competition) and somatic trait anxiety (physical reactions of anxiety). It comprises three subscales: i) Somatic anxiety (five items; $\alpha=.85$ ): focusing on indices of autonomic arousal centred in the stomach and muscles (e.g., "My body feels tense"); ii) Worry (five items; $\alpha=.88$ ): evaluating the sense of poor performance and the resulting negative consequences (e.g., "I worry that I will not play well"); iii) Concentration disruption (five items; $\alpha=.82$ ): reflecting the difficulties in concentrating on task-relevant activities (e.g., "I lose focus on the game"). Subscale scores were obtained by summing the scores on each scale. It was also possible to calculate a global score which resulted from the sum of the three subscale scores $(\alpha=.89)$.

Task and Ego Orientation in Sport Questionnaire (TEOSQ; Duda, 1992; Duda \& Whitehead, 1998; Portuguese adaptation by Cruz \& Matos, 1997). This instrument was designed to assess individual differences in the tendency for task and ego involvement, as defined in Nicholls theory $(1984,1989)$. It comprises 13 items answered on a five-point Likert-scale ranging from 1 ("Strongly disagree") to 5 ("Strongly agree"), subsequently organised in two dimensions: i) Ego orientation (six items; $\alpha=.87$ ): assessing the purpose of demonstrating superior ability to others, being achievement construed in norm referenced terms (e.g., "I feel successful in sport when the others can't do as well as me"); ii) Task orientation (seven items; $\alpha=$ .85): reflecting the purpose of gaining skill or knowledge and performing at one's best (e.g., "I feel successful in sport when I work really hard"). Subscale scores were obtained by adding item scores and the sum was divided by the total number of items forming each scale.

Cognitive Evaluation of Sport-Threat Perception (CES-TP; Cruz, 1996). The CES-TP is comprised by eight items, measured on a five-point Likert-scale ranging from 1 ("It doesn't apply to me") to 5 ("It applies to me") and it assesses primary cognitive appraisal in terms of athletes' threat perception about competition (e.g., failing or making mistakes at crucial moments in competition). In other words, it analyses "what is at stake" in competition for each athlete and which can cause stress. The score was obtained by summing the scores on the eight items $(\alpha=.88)$.

Self-Presentation Exercise Questionnaire (SPEQ; Gammage et al., 2004; Portuguese adaptation by Cruz, 2006). 
This instrument is used in sport and exercise contexts (Cruz, 2006) being adapted from the original work of Gammage et al. (2004) on the Self-Presentation Exercise Questionnaire (SPEQ). It comprises eight items answered on a six-point Likert-scale ranging from 1 ("Strongly disagree") to 6 ("Totally agree"). It assesses self-presentational processes in two personal dimensions: i) Impression construction (four items; $\alpha=.86$ ): expressing athletes' behaviors to create the impression of being fit, toned and of being an exerciser (e.g., "I want others to see me with friends who are exercising"); ii) Impression motivation (four items; $\alpha=$ .82): assessing athletes' desire to be perceived as being fit, toned or as being an exerciser (e.g., "I try to appear toned of fit to others"). Subscale scores were obtained by adding item scores and the sum was divided by the total number of items forming each subscale.

\section{Procedure}

We used for this study a convenience sample, and the athletes were randomly chosen. However, an effort was made in order to balance the distributions of gender and type of sport (individual vs. collective). In addition, by establishing that athletes had to have participated in national and official competitions as an inclusion criterion, we have also guaranteed balance in terms of the competitive level of demand to which they would have been subjected to.

Coaches have received an initial request explaining the research goals and data collection procedures. Subsequently, athletes were invited to participate in the study with the guarantee that their data would be anonymous and confidential. Finally, an informed consent was signed either by the athletes or, in case they were less than 18 years old, by their parents/guardians.

Data collection took place either before or after a training session, during the days preceding competition. Coaches were not present while the athletes completed the assessment protocol. In total, 361 questionnaires were administered, 299 of them having been received and considered valid, which indicates a high return rate $(82.8 \%)$.

\section{Data analysis}

We started with an exploratory data analysis, which has revealed that for the majority of the variables the assumptions for using parametric tests were met. Whenever this was not the case, the approach has been computing both parametric and their equivalent non-parametric tests, as advised by Fife-Schaw (2006). Given the conclusions drawn from both set of tests were the same in all cases, only the parametric tests' results will be presented, as these are more robust and allow us to use multivariate analysis, while reducing the number of tests carried out and, therefore, the probability of the Type I error.
Data analyses progressed as following. First, we tested for differences in the subscales of the Eating Disorder Examination Questionnaire, taking into consideration some personal and sport variables of the athletes. For that, we have used a two-way ANOVA for the global score of the EDE-Q, and a multivariate analysis of variance (MANOVA) for the four scales of EDE-Q. A 2 X 3 design was adopted in testing the relationship between gender (male and female) and competitive level (juvenile, junior and senior), and a design 2 X 2 in testing the relationship between the type of sport (individual and collective) and sport records (with and without national titles).

Second, we examined the differences in eating disordered behaviors according to the perception of ideal body weight. On this respect, athletes were divided in three groups: those who would like to weigh less $(n=155,51.8 \%)$; those who expressed a desire to have the same weight $(n=55,18.4 \%)$ and those who would like to weigh more $(n=67 ; 22.4 \%)$. In this case, we used one-way ANOVA to test the differences between groups in the global score of EDE-Q and multivariate analysis of variance (MANOVA) for the four scales of EDE-Q. In the cases where we found differences between groups, post-hoc Scheffé tests were subsequently used.

Thirdly, we analyzed the differences in the psychological variables according the tendency of the athletes for eating disordered behaviors. In this case, we tried to assess the differences in the psychological dimensions (SCQ, SAS-2, TEOSQ, CES-TP and SPEQ) according the scores obtained in EDE-Q global score by creating two comparison groups: one with the lowest scores and one with the highest scores in the EDE-Q global score, applying comparative analysis for independent groups ( $t$-test for independent samples to test the differences in the global scores of the instruments) and multivariate analysis of variance (MANOVA) (to test the differences in the specific dimensions of the instruments with more than one subscale). On this differentiation, we tried to balance the elements of each group, following suggestions from other studies where this procedure was also applied (Lipsey, Barton, Hulley, \& Hill, 2006).

Finally, we used regression analysis with blocked entry procedures in order to examine the influence of the psychological variables (SCQ, SAS-2, TEOSQ, CESTP and SPEQ) in the four dimensions of EDE-Q. In this analysis, the effects of relevant socio-demographic and sports' characteristics of the athletes were controlled for.

\section{Results}

\section{Attitudes and risk behaviors associated with eating disordered behaviors}

Table 1 presents the frequencies of the six diagnostic items evaluated in the EDE-Q. Behaviors are mainly 
Table 1

Frequency of occurrence of diagnostic indicators associated with eating disordered behaviors

\begin{tabular}{|c|c|c|c|c|}
\hline Behaviors & $N$ & $\begin{array}{c}\text { It never occurred } \\
n(\%)\end{array}$ & $\begin{array}{c}\text { It occurred* } \\
n(\%)\end{array}$ & Range \\
\hline Ingestion of an unusually large amount of food & 294 & $130(44.2)$ & $164(55.8)$ & $0-28$ \\
\hline Episodes of eating too much and feelings of loss of control & 295 & $184(62.4)$ & $111(37.6)$ & $0-28$ \\
\hline Feelings of losing control over eating & 292 & $208(71.2)$ & $84(28.8)$ & $0-28$ \\
\hline $\begin{array}{l}\text { Practicing excessive physical exercise as a way to control } \\
\text { weight, body shape and to burn calories }\end{array}$ & 295 & $243(82.4)$ & $52(17.6)$ & $0-28$ \\
\hline Inducing vomiting to control weight or body shape & 294 & $290(98.6)$ & $4(1.4)$ & $0-10$ \\
\hline Ingestion of laxatives to control weight or body shape & 295 & $294(99.7)$ & $1(.3)$ & $0-15$ \\
\hline
\end{tabular}

*Note - These values are referred to "at least one occurrence" of the behavior in the last four weeks.

related to the ingestion of a significant amount of food and the feeling of loss of control over eating, both potential indicators of compulsive overeating ("bingeing") (percentages of "at least one occurrence" between $55.8 \%$ and $28.8 \%$, respectively).

In what concerns the problematic results in the EDE-Q, we found the following values of clinical significance for each subscale: restraint with four athletes (1.3\%), eating concern with one athlete $(.3 \%)$, shape concern with fourteen athletes $(4.6 \%)$, and weight concern with fifteen athletes (5\%). Any athlete has demonstrated problematic values in all the subscales simultaneously. Combining the results of different subscales, two female athletes displayed problematic values in the restrain, shape concern, and weight concern $(.7 \%)$. With more salient results, eleven athletes $(3.7 \%)$, ten of which were females, met clinical criteria simultaneously in shape concern and weight concern.

\section{Differences in eating disordered behaviors according some personal and sport variables}

In this case, we analysed the differences in the EDE-Q subscales taking into consideration some personal and sport variables of the athletes.

Starting with the first group of variables (gender and competitive level) in the four dimensions of EDE-Q, there were no significant differences between groups, Wilks' $\lambda=.98, F(8,580)=.67, p=.717$. However, univariate tests point out to significant gender differences, with women assuming greater values in all the dimensions of the EDE-Q (see Table 2). In what concerns the EDE-Q global score, no differences in the interaction of variables were found, $F(2,293)=1.77 ; p=.172$ but we should mention the main effect of the gender variable, $F(1,293)=39.95 ; p<.001$, with women scoring higher in this dimension (Table 2).
In the second group of variables (type of sport and sport records), there were no significant differences between groups in the four dimensions of EDE-Q, Wilks' $\lambda=.99$, $F(4,288)=.40, p=.812$. However, a main effect in the sport records variable was detected, Wilks' $\lambda=.93, F(4,288)=$ $5.61, p<.001$, being athletes with a more successful career (with a record of national champion) that assumed a higher tendency for restraint (Table 2). In what concerns the EDE-Q global score, no interaction effects were found, $F(1,291)=1.43 ; p=.233$.

\section{Differences in eating disordered behaviors according the perception of ideal weight}

Next, the effects of athletes' perception of ideal body weight on the various facets of the EDE-Q were investigated.

Starting with the four dimensions of EDE-Q, we found differences between the groups, Wilks' $\lambda=.70, F(8,542)=$ 13.30, $p<.001$. Subsequent univariate tests revealed that athletes with the desire to weight less had different results than the other two groups (e.g., desire of having the same and more weight). Taking into consideration the average values of the subscales, it was possible to conclude that the group with the desire to weigh less scored higher on restrain, eating concern, shape concern, and weight concern (see Table 3). There were also differences in the EDE-Q global score, $F(2,274)=47.65 ; p<.001$, and again the athletes with the desire to weight less assumed higher scores (Table 3).

\section{Differences in the psychological dimensions according the tendency for eating disordered behaviors}

The next step was to explore whether the psychological variables (SCQ, SAS-2, TEOSQ, CES-TP and SPEQ) 
Table 2

Mean, standard deviation and values of the univariate tests of EDE-Q: Differences according personal and sport variables

\begin{tabular}{|c|c|c|c|}
\hline & $\begin{array}{l}\text { Female } \\
(n=146) \\
M(S D)\end{array}$ & $\begin{array}{c}\text { Male } \\
(n=153) \\
M(S D)\end{array}$ & $\begin{array}{c}\boldsymbol{F} \\
(1,293)\end{array}$ \\
\hline EDE-Q: Restraint & $1.08(1.16)$ & $.57(.96)$ & $16.07 * * *$ \\
\hline EDE-Q: Eating concern & $.52(.75)$ & $.30(.61)$ & $8.94 * *$ \\
\hline EDE-Q: Shape concern & $1.62(1.45)$ & $.59(.91)$ & $52.51 * * *$ \\
\hline EDE-Q: Weight concern & $1.56(1.47)$ & $.62(.90)$ & $43.62 * * *$ \\
\hline \multirow[t]{2}{*}{ EDE-Q - Global score } & $1.19(1.08)$ & $.52(.74)$ & $39.34 * * *$ \\
\hline & $\begin{array}{l}\text { Without sport records } \\
\qquad \begin{array}{c}(n=209) \\
M(S D)\end{array}\end{array}$ & $\begin{array}{l}\text { With sport records } \\
\qquad \begin{array}{l}(n=86) \\
M(S D)\end{array}\end{array}$ & $\begin{array}{c}\boldsymbol{F} \\
(1,291)\end{array}$ \\
\hline EDE-Q: Restraint & $.70(.99)$ & $1.07(1.24)$ & $7.91 * *$ \\
\hline
\end{tabular}

$* * p<.01 ; * * * p<.001$

Table 3

Mean, standard deviation and values of the univariate tests of EDE-Q: Differences according to athletes'perception of ideal weight

\begin{tabular}{|c|c|c|c|c|}
\hline & $\begin{array}{l}\text { Less weight } \\
\begin{array}{l}M(S D) \\
n=155\end{array}\end{array}$ & $\begin{array}{c}\text { Same weight } \\
\begin{array}{c}M \quad(S D) \\
n=55\end{array}\end{array}$ & $\begin{array}{l}\text { More weight } \\
\begin{array}{c}M \quad(S D) \\
n=67\end{array}\end{array}$ & $\begin{array}{c}\boldsymbol{F} \\
(2,274)\end{array}$ \\
\hline EDE-Q: Restraint & $1.28(1.19)$ & $.32(.59)$ & $.28(.73)$ & $32.95 * * *$ \\
\hline EDE-Q: Eating concern & $.62(.80)$ & $.12(.25)$ & $.18(.47)$ & $17.52^{* * *}$ \\
\hline EDE-Q: Shape concern & $1.65(1.46)$ & $.32(.46)$ & . $49(.79)$ & $37.65^{* * *}$ \\
\hline EDE-Q: Weight concern & $1.71(1.40)$ & $.22(.40)$ & $.44(.72)$ & $51.25^{* * *}$ \\
\hline EDE-Q - Global score & $1.31(1.07)$ & $.25(.32)$ & $.35(.54)$ & $47.65^{* * *}$ \\
\hline
\end{tabular}

$* * * p<.001$

varied according to the athletes' tendency for eating disordered behaviors.

Starting by the Sport Anxiety Scale, significant differences in the three dimensions of the instrument were found, Wilks' $\lambda=.72, F(3,78)=10.28, p<.001$. Univariate tests showed that athletes with a higher tendency for eating disordered behaviors exhibit more somatic anxiety, worry, and concentration disruption. Likewise, those athletes scored higher in the EDE-Q global score, $t=-5.25 ; 80 ; p<.001$.

With respect to the Task and Ego Orientation in Sport Questionnaire, there were no differences between the groups, Wilks' $\lambda=.94, F(2,81)=2.74, p=.071$. However, the univariate tests indicated that athletes with a higher tendency for eating disordered behaviors assumed more task orientation.
In terms of the self-presentation processes, differences were found between the two groups, Wilks' $\lambda=.84, F(2,80)$ $=7.37, p<.01$, with univariate tests revealing that the athletes with a higher scores in the EDE-Q global score demonstrated a higher tendency to impression motivation.

Differences were also found in the two subscales of the Sport Condition Questionnaire. In this case, athletes with lower scores in the EDE-Q global score expressed more satisfaction with their body shape and physical appearance, $t=8.58 ; 81 ; p<.001$ and less weight-related coach pressure, $t=-4.16 ; 73 ; p<.001$.

Finally, athletes with higher threat perception (CES$\mathrm{TP}$ ), got higher values in EDE-Q global score, $t=-4.75$; $81 ; p<.001$.

All the significant results found in these analyses can be seen in Table 4. 
Table 4

Mean, standard deviation and values of the univariate tests of the psychological dimensions: Differences according to EDE-Q scores

\begin{tabular}{|c|c|c|c|c|c|}
\hline & \multicolumn{2}{|c|}{ Lowest scores } & \multicolumn{2}{|c|}{ Highest scores } & \multirow[t]{2}{*}{$\boldsymbol{F}$} \\
\hline & $M(S D)$ & $n$ & $M(S D)$ & $n$ & \\
\hline $\begin{array}{l}\text { SCQ: Satisfaction with body shape and physical } \\
\text { appearance }\end{array}$ & $4.08(.58)$ & 41 & $2.78(.78)$ & 42 & -- \\
\hline SCQ: Weight-related coach pressure & $1.42(.69)$ & 41 & $2.19(.99)$ & 42 & -- \\
\hline $\begin{array}{l}\text { SAS-2: Somatic anxiety } \\
\text { SAS-2: Worry } \\
\text { SAS-2: Concentration disruption } \\
\text { SAS-2: Global score }\end{array}$ & $\begin{array}{r}7.62(2.70) \\
11.55(4.14) \\
5.83(2.17) \\
25.00(7.53)\end{array}$ & $\begin{array}{l}42 \\
42 \\
42 \\
42\end{array}$ & $\begin{array}{r}9.90(3.03) \\
15.78(2.96) \\
7.35(2.51) \\
33.03(6.22)\end{array}$ & $\begin{array}{l}40 \\
40 \\
40 \\
40\end{array}$ & $\begin{array}{l}(1,80) \\
12.93 * * \\
28.07 * * * \\
8.59 * * \\
--\end{array}$ \\
\hline TEOSQ: Task orientation & $3.83(.82)$ & 42 & $4.20(.59)$ & 42 & $\begin{array}{r}(1,82) \\
5.55^{*}\end{array}$ \\
\hline CES-TP: Threat Perception & $2.70(1.05)$ & 41 & $3.65(.74)$ & 42 & -- \\
\hline SPEQ: Impression motivation & $4.04(1.23)$ & 41 & $4.94(.88)$ & 42 & $\begin{array}{l}(1,81) \\
14.81 * * *\end{array}$ \\
\hline
\end{tabular}

$* p<.05 ; * * p<.01 ; * * * p<.001$

\section{Prediction of athletes' eating disordered behaviors}

Finally, the influence of the psychological variables (SCQ, SAS-2, TEOSQ, CES-TP and SPEQ) in the four dimensions of EDE-Q was examined, after controlling personal and sport variables of the athletes.

Starting with the restraint subscale, in the first block, we found differences between genders, $F(1,286)=16.01$, $p<.001$ explaining $5 \%$ of the variance $\left(\mathrm{R}^{2}{ }_{\mathrm{Adj}}=.05\right)$. In this case, women reported higher restraint, $\beta=.23, t=4.00, p$ $<.001$. When the sport records was added to the regression (second block), the model accounted for $8 \%$ of the variance, $F(2,285)=12.06, p<.001\left(\mathrm{R}_{\text {Adj }}^{2}=.07\right)$. Athletes with the best sport records (national champions) reported higher restraint, $\beta=.16, t=2.78, p<.01$. The inclusion of the psychological dimensions in the third block resulted in a significant model, $F(6,281)=19.95, p<.001$ accounting for $30 \%$ of the variance $\left(\mathrm{R}_{\mathrm{Adj}}^{2}=.28\right)$. Thus, after taking into account the effects of gender and sport records, athletes' impression motivation, satisfaction with body shape and physical appearance, and threat perception emerged as significant predictors. Thus, higher restraint was predicted by higher impression motivation, $\beta=.15, t=2.75, p<.01$ and threat perception, $\beta=.15, t=2.64, p<.01$, and by less satisfaction with body shape and physical appearance, $\beta=-.38, t=-7.38, p<.001$.

In the case of eating concern, in the first block we found significant differences between genders, $F(1,286)=8.90, p$ $<.01$ explaining $3 \%$ of the variance $\left(\mathrm{R}^{2}{ }_{\mathrm{Adj}}=.03\right)$. Again, female athletes expressed higher eating concern, $\beta=.17$, $t=2.98, p<.01$. The inclusion of the psychological dimensions in the second block resulted in a significant model, $F(2,285)=32.34, p<.001$ accounting for $19 \%$ of the variance $\left(\mathrm{R}^{2}{ }_{\mathrm{Adj}}=.18\right)$. After controlling the effects of gender, satisfaction with body shape and physical appearance emerged as significant predictor. Thus, higher eating concern was predicted by less satisfaction with body shape and physical appearance, $\beta=-.40, t=-7.36, p<.001$.

Regarding shape concern, in the first block we found significant gender differences, $F(1,267)=65.59, p<.001$ explaining $20 \%$ of the variance $\left(\mathrm{R}^{2}{ }_{\mathrm{Adj}}=.19\right)$. In this case, females reported higher shape concern, $\beta=.44, t=8.10, p<$ .001 . In the second block we controlled for the perception of ideal weight and the model explained $32 \%$ of the variance, $F(2,266)=61.30, p<.001\left(\mathrm{R}_{\text {Adj }}^{2}=.31\right)$. Athletes with the desire to weigh less assumed higher shape concern, $\beta=$ $.36, t=6.78, p<.001$. The inclusion of the psychological dimensions in the third block resulted in a significant 
model, $F(5,263)=67.94, p<.001$ accounting for $56 \%$ of the variance $\left(\mathrm{R}_{\mathrm{Adj}}^{2}=.56\right)$. After controlling the effects of gender and the perception of ideal weight, impression motivation, cognitive anxiety (worry) and satisfaction with body shape and physical appearance emerged as significant predictors. Thus, higher shape concern was predicted by higher impression motivation, $\beta=.15, t=3.59, p<.001$ and cognitive anxiety (worry), $\beta=.20, t=4.51, p<.001$, and by less satisfaction with body shape and physical appearance, $\beta=-.43, t=-9.53, p<.001$.

Finally, in the case of weight concern, in the first block, once again we found significant gender differences, $F(1,267)=46.95, p<.001$ explaining $15 \%$ of the variance $\left(\mathrm{R}^{2}{ }_{\mathrm{Adj}}=.15\right)$, with females expressing higher weight concern, $\beta=.39, t=6.85, p<.001$. In the second block we controlled the perception of ideal weight and the model explained $33 \%$ of the variance, $F(2,266)=65.58, p<.001\left(\mathrm{R}^{2}{ }_{\text {ddj }}=\right.$ $.33)$. Athletes with the desire to weigh less reported higher weight concern, $\beta=.44, t=8.47, p<.001$. The inclusion of the psychological dimensions in the third block resulted in a significant model, $F(6,262)=59.94, p<.001$ accounting for $58 \%$ of the variance $\left(\mathrm{R}^{2}{ }_{\mathrm{Adj}}=.57\right)$. After controlling the effects of gender and perception of ideal weight, impression motivation, somatic anxiety and satisfaction with body shape and physical appearance emerged as significant predictors. Thus, higher weight concern was predicted by higher impression motivation, $\beta=.12, t=3.05, p<.01$ and somatic anxiety, $\beta=.22, t=5.32, p<.001$, and by less satisfaction with body shape and physical appearance, $\beta=-.42, t=-9.47, p<.001$.

\section{Discussion}

Although eating disorders represent a topic of great interest in non-sport populations, research focusing on athletes is still scarce, particularly in the analysis of the psychological factors that can be related with such problematic behavior (Petrie \& Greenleaf, 2007). Thus, this study examined the relationship between eating disordered behaviors and psychological factors in a sample of Portuguese athletes, taking into consideration the importance of personal and sport characteristics of the participants.

Starting with the attitudes and problematic behaviors associated with eating disorders, the first aspect to point out was the fact that no athlete reached simultaneously clinical results in the four dimensions of the Eating Disorder Examination Questionnaire. Relating this result with the literature, and depending on the measures that have been applied, studies have found quite distinct results in terms of prevalence, ranging from low or residual values (between $1 \%$ and $7 \%$ ) (Johnson et al., 1999; Petrie, Greenleaf, Carter, \& Reel, 2007; Reel, SooHoo, Doetsch, Carter, \& Petrie, 2007; Sanford-Martens et al., 2005) up to high percentages (between 15\% and 20\%) (Beals \& Hill, 2006; Hulley \&
Hill, 2001; Sundgot-Borgen, 1994a). In what concerns Portugal, to our knowledge, there are no estimates of eating disordered behaviors' prevalence in sport contexts. As to non-sport population, in a study carried out with a large sample of female adolescents, Machado, Machado, Gonçalves, and Hoek (2007) found a prevalence of about $3 \%$ of eating disorders.

Interestingly, and according to the results of each subscale of the EDE-Q, the dimensions that assumed higher clinical relevance were shape concern and weight concern, both representing significant domains to athletes and sport success. Likewise, Pasman, and Thompson (1988) examined eating disorders in a comparative study between athletes (athletics and weightlifting) and non-athletes, and concluded that athletes assumed the highest rates in the subscale "Drive for Thinness" of the Eating Disorders Inventory (EDI, Garner, Olmsted, \& Polivy, 1983). These data reinforces that the understanding of eating disorders in sport contexts should consider the specific expectations and demands placed upon athletes, who in turn convert such problematical behaviors into common practices.

In this same way, the influence of sport setting was also felt in the frequency of problematic behaviors associated with eating disorders (diagnostic items). In fact, while we found almost no record of behaviors related with vomiting inducing and laxatives using, the same was not verified to the ingesting of a large amount of food, which was assumed at least one time for half of the athletes in the last four weeks. Regarding the experience of losing control over eating, results ranged between $29 \%$ and $38 \%$, while the practice of excessive physical exercise resulted in around $18 \%$. Thus, while the act of eating (and subsequent loss of sense of control) reached very significant values, behaviors such as induction of vomiting and ingestion of laxatives evidenced very low frequencies. These last results stress the inexistence of a clinical pattern of eating behavior by the athletes, especially when they are compared with other studies. For example, Rosen, McKeage, Hough, and Curly (1986) analyzed the unhealthy methods of weight control in a sample of ten female college sports and found that $32 \%$ of athletes displayed at least one risk behavior (e.g., induction of vomiting, use of diuretics and laxatives, uncontrolled intake of drugs for weight loss, excessive exercise and strict dieting). Similarly, Anshel (2004) in a study with ballet students found high percentages for a range of problematic behaviors, such as, diets (29.6\%), the use of laxatives (11\%), the tendency for skipping meals (25.9\%), and the induction of vomiting (14.8\%).

With respect to individual and sport variables, this study suggested a greater willingness of women for the tendency toward eating disordered behaviors (in all dimensions of the EDE-Q). This result is not surprising, since the literature has shown a higher prevalence of eating problems in women (Hausenblas \& McNally, 2004; Sanford-Martens et al., 2005; Stoutjesdyk \& Jevne, 1993). In fact, the need to 
study eating disorders in female athletes lead the American College of Sports Medicine (ACSM) (Otis, Drinkwater, Johnson, Loucks, \& Willmore, 1997) to formulate the concept of "Female Athlete Triad", that includes three distinct elements: eating disorder, amenorrhea and osteoporosis (Mantoanelli, Vitalli, \& Amancio, 2002). This problem starts with the desire of female athletes in maintaining a low weight, which contributes to the development of eating disorders. As a consequence, they have problems related with amenorrhea and osteoporosis. This association was demonstrated in a study conducted with college athletes from the U.S., with athletes considered at risk for an eating disorder reporting more frequently irregularities in the menstrual cycles and more bone injuries during their sport career (Beals \& Manore, 2002). Given this evidence, researchers are unanimous in highlighting the need for offering a multidisciplinary intervention to the female athletes, including education and training, nutritional prescribing, support in the design of training, psychological therapy, and eventually, specialized medical help (Sanborn, Horea, Siemers, \& Dieringer, 2000; Waldrop, 2005; West, 1998).

With regards to sports results, our study revealed that athletes with the best sport records were more likely to report restraint behaviors. In this case, the relationship with literature is more complex and difficult, as there are no clear indications whether the possibility of the competitive level (e.g., recreation, regional, national or international) represent a risk factor for eating disorders (Hausenblas \& McNally, 2004). Hence, Byrne and McLean (2001) advocate the need for investigations focusing on athletes included in demanding competitive situations, both nationally and internationally. In our case, the vast majority of athletes were competing in top leagues of their sports, and from this point of view, this study may represent an improvement in the understanding of this problem. Thus, the fact that athletes with the best sport records (e.g., national champions) expressed a greater tendency for restraint is in line with the hypothesis that practitioners included in more demanding competitions (elite) tend to report a greater tendency for risk eating behaviors (Picard, 1999; Stoutjesdyk \& Jevne, 1993).

Another interesting finding was the absence of differences in eating disordered behaviors depending on the type of sport practiced by athletes. In fact, when the differentiation between individual and collective sports was made, we tried to distinguish between athletes more susceptible to pressures related to body weight (included in individual sports) and athletes where this pressure was not so evident (included in team sports). In this sense, some studies have tried to differentiate between practitioners included in sports where athletic performance appears to be more dependent on weight control (e.g., gymnastics, swimming, long running, rowing, skating, etc.), and other sports where this factor does not seem so determinant (e.g., football, basketball, handball, hockey, etc.) (Byrne \& McLean, 2001; Sundgot-Borgen, 1994b). But in this case the indications seems to be inconsistent, as there are results confirming the propensity of athletes subjected to a higher body weight pressure to be at a greater risk for eating disorders (Davis \& Cowles, 1989; Petrie, 1996), while in other studies, such as in our case, no differences were found (Hausenblas \& McNally, 2004; Roll et al., 2007; SanfordMartens et al., 2005).

In what concerns the importance of psychological factors in eating disordered behaviors, one of the most striking aspects of this study refers to the fact that athletes with the desire for weighing less (51.8\% of participants) displayed a greater propensity for eating disordered behaviors, compared with those athletes who expressed their intention to maintain or even increase their weight. This is an interesting finding because research has demonstrated that athletes who express their willingness to lose weight experience greater body dissatisfaction (Blowers, Loxton, Grady-Flessa, Occhipinti, \& Dawe, 2003) which, in turn, can increase the risk for diets and unhealthy weight control behaviors (Sinton \& Birch, 2005). This pattern of association has also been demonstrated in other contexts. For example, Canpolat, Orsel, Akdemir, and Ozbay (2005) in a study with adolescents from Turkey, found that a body ideal of thinness, low self-esteem and physical self-concept had significant effects on body dissatisfaction. This is even more relevant because body dissatisfaction can place young people at risk for an eating disorder (Keel, Fulkerson, \& Leon, 1997; Stice, Presnell, \& Spangler, 2002).

Moreover, the distinction between athletes with higher and lower scores on the EDE-Q (Lipsey et al., 2006) confirmed the existence of differences in most of the psychological dimensions assessed in this study. In fact, athletes with the highest scores on EDE-Q (e.g., more prone to eating disorders), expressed lower satisfaction with body shape and physical appearance and higher perception of height-related coach pressure, anxiety (in all dimensions assessed), task orientation, threat perception and impression motivation. In other words, we found a less positive pattern of psychological functioning in athletes with higher tendency for eating disorders. The relationship of this finding with the literature is somewhat problematic, since there are not many studies about the psychological dimensions that we assessed (e.g., anxiety, motivation, threat perception and self-presentation). The relationship with coach attitudes is more evident, because there are indications that coaches' critical comments, namely instructions for athletes to lose weight, represent a factor that can increase the vulnerability to eating disorders (Kerr, Berman, \& De Souza, 2006; Muscat \& Long. 2008). In terms of self-presentation, research has shown its importance in sport contexts (Ginis \& Leary, 2004; Hausemblas, Brewer, \& Van Raalte, 2004), which raises the hypothesis of being associated with eating behaviors. This hypothesis is based 
on the fact that athletes who expressed greater willingness to be perceived as being fit, toned or as being an exerciser (impression motivation), showed a greater tendency for eating disorders. In terms of motivation, our results suggested that athletes more prone to eating disordered behaviors reported higher task-orientation. This finding is somewhat discrepant when compared with the research on the impact of motivational orientations, as task orientation tends to be associated with more positive reactions in the sport activity (Roberts, 2001). However, De Bruin, Bakker and Oudejans (2009) in a study with dancers and gymnasts, found that both task and ego orientations were related with more problematic behaviors, namely the predisposition to dieting, the use of unhealthy methods of weight control, perfectionism and the perception of pressure from peers. In our case, the impact of motivational orientation was not so obvious, and as we shall see, both dimensions were not significant in the prediction of EDE-Q factors. In this sense, it is necessary that future research analyze the contribution of motivational orientation in eating behaviors of athletes.

In the last group of analysis, we observed the dimensions that would best predict eating disorders. To do this we followed the suggestion of Petrie et al. (2007) that highlighted the need for identifying the psychological factors associated with eating disorders, as they might contribute to place athletes at greater risk for such problems.

The results showed that the assessed psychological dimensions constituted good predictors of the EDE-Q dimensions, particularly in the cases of weight concern, shape concern and restraint. The control of personal and sport variables in the regression models confirmed, as we saw earlier, the importance of gender differences, sport records and perception of ideal weight, which should be taken into account in the understanding of eating disorders in sport contexts. In what concerns the psychological variables, and based in the results that were significant, we should stress the importance of satisfaction with body shape and physical appearance ("entered" in all the regression models), impression motivation ("entered" in four regression models), somatic anxiety and worry ("entered" in three regression models), threat perception ("entered" in one regression models), and weight-related coach pressure ("entered" in one regression models).

Starting with the satisfaction with body shape and physical appearance, our results are in line with findings from outside the sport world, which highlights this variable as a key factor in the understanding of eating disorders (Attie \& Brooks-Gunn, 1989; Coric \& Murstein, 1993; Killen et al., 1996; Klemchuk, Hutchinson, \& Frank, 1990). For example, a study with female Afro-American students found that body mass index, body dissatisfaction and low self-esteem were significantly related to bulimic symptoms, explaining $29 \%$ of its variance (Lester \& Petrie, 1998).

In relation to anxiety, this study confirmed the relevance of somatic and cognitive dimensions in the prediction of eating disorders, particularly in the case of shape concern and weight concern. In one of the few studies done on this topic with female athletes and non-athletes, DenomHolm et al. (2009) also found that athletes who competed in the most stressful situations, and had higher levels of sport anxiety, experienced more bulimia symptoms and body dissatisfaction. The importance of these predictions is further enhanced by threat perception, with athletes who evaluated the competition as more negative and stressful being at greater risk for eating disorders. The relationship of this result with anxiety is obvious, since the processes of cognitive evaluation, which includes the threat perception, are associated with emotional responses and adaptation to stress (Lazarus, 2000).

Regarding self-presentation, this study showed the importance of this factor in the understanding of eating disordered behaviors. More specifically, we observed that the cognitive dimension of self-presentation (impression motivation) had a major influence in the explanation of eating disorders, characterized by the desire of athletes giving the positive impression of being fit, toned or being an exerciser. These data may contradict some predictions of Ginis and Leary (2004) on the possibility of selfpresentation having different effects depending on the image that people are trying to convey. In fact, these authors put forward the hypothesis that people who value healthy lifestyles take more positive actions for their wellbeing and social adjustment (e.g., exercise). In our case, the search of a positive impression (being perceived in good shape and looking as an athlete) can also result in risky behavior to health.

Finally, coaching attitudes also gained relevance in this study, being clear that coaches' negative postures and pressure to be fit and in good shape predicts the tendency for athletes' eating disordered behaviors. Thus, it makes sense to develop training programs for coaches about the relationship between their actions and eating disordered behaviors in athletes, and instruct them into more positive interactions with athletes.

In summary, although the prevalence of attitudes and risk behaviors associated with eating disordered behaviors were not significant in this study, the results of its relationship with personal, psychological and sport variables were evident. In fact, the understanding of this condition can be facilitated by considering these aspects, and by paying special attention to women and athletes with the best sport records. In addition, some psychological variables, such as the perception of ideal weight, the body satisfaction, the cognitive evaluation of the competition, the emotional reactions and processes of self-presentation, together with some relational variables (e.g., interaction with the coach) seem to represent core domains in the explanation of this problem. Considering all the results, it should be highlight the relevance of studying the relationship between eating disordered behaviors (even if 
they are not considered dysfunctional from a clinical point of view) and the athletes' health and welfare (Johnson, 1994; Sanford-Martens et al., 2005).

Future research should complement athletes' selfreported data about weight and height with objective measures. In fact, despite the guarantee of anonymity and confidentiality in the use of the information given to the participants in this study, unreliable information may still have been provided. In this way, it could be a good idea to weigh and measure height of the athletes when collecting the other psychological measures (DiBartolo \& Shaffer, 2002). On the other hand, it is evident the need to further examine the impact of the psychological variables in eating disordered behaviors, since as this study showed some unexpected results. For example, impression motivation (which was related to an increased tendency for eating disordered behaviors) also tends to be associated with positive effects, particularly in the prevention of risk behaviors to health (see Ginis \& Leary, 2004). The analysis of these relationships can not only improve our understanding about the impact of psychological factors on eating disorders but also help in the prevention of this problem in sports contexts.

\section{References}

Anshel, M. H. (2004). Sources of disordered eating patterns between ballet dancers and non-dancers. Journal of Sport Behavior, 27, 115-133.

Ashley, C. D., Smith, J. F., Robinson, J. B., \& Richardson, M. T. (1996). Disordered eating in female collegiate athletes and collegiate females in an advanced program of study: A preliminary investigation. International Journal of Sport Nutrition, 6, 391-401.

Attie, I., \& Brooks-Gunn, J. (1989). Development of eating problems in adolescent girls: A longitudinal study. Developmental Psychology, 25, 70-79. doi:10.1037/00121649.25.1.70

Bamber, D., Cockerill, I. M., Rodgers, S., \& Carroll, D. (2003). Diagnostic criteria for exercise dependence. British Journal of Sports Medicine, 37, 393-400. doi:10.1136/bjsm.37.5.393

Beals, K. A., \& Hill, A. K. (2006). The prevalence of disordered eating, menstrual dysfunction, and low bone mineral density among US collegiate athletes. International Journal of Sport Nutrition and Exercise Metabolism, 16, 1-23.

Beals, K. A., \& Manore, M. M. (2002). Disorders of the female athlete triad among collegiate athletes. International Journal of Sport Nutrition and Exercise Metabolism, 12, 281-93.

Biddle, S. J. H., \& Mutrie, N. (2001). Psychology of physical activity: Determinants, well-being and interventions. London: Routledge.

Blowers, L. C., Loxton, N. J., Grady-Flesser, M., Occhipinti, S., \& Dawe, S. (2003). The relationship between socio-cultural pressure to be thin and body dissatisfaction in preadolescent girls. Eating Behaviors, 4, 229-244. doi:10.1016/S14710153(03)00018-7

Bruin, A. P., Oudejans, R. R., \& Bakker, F. C. (2007). Dieting and body image in aesthetic sports: A comparison of Dutch female gymnasts and non-aesthetic sport participants. Psychology of Sport and Exercise, 8, 507-520. doi:10.1016/j. psychsport.2006.10.002

Buckworth, J., \& Dishman, R. K. (2002). Exercise Psychology. Champaign, IL: Human Kinetics.

Byrne, S., \& McLean, N. (2001). Eating disorders in athletes: A review of the literature. Journal of Science and Medicine in Sport, 4, 145-159. doi:10.1016/S1440-2440(01)80025-6

Byrne, S., \& McLean, N. (2002). Elite athletes: Effects of the pressure to be thin. Journal of Science and Medicine in Sport, 5, 80-94. doi:10.1016/S1440-2440(02)80029-9

Canpolat, B. I., Orsel, S., Akdemir, A., \& Ozbay, M. H. (2005). The relationship between dieting and body image, body ideal, self-perception, and body mass index in Turkish adolescents. International Journal of Eating Disorders, 37, 150-155. doi:10.1002/eat.20081

Coric, D., \& Murstein, B. (1993). Bulimia nervosa: Prevalence and psychological correlates in a college community. Eating Disorders, 1, 39-51.

Cruz, J. F. (1996). Stress, ansiedade e rendimento na competição desportiva [Stress, anxiety and sport performance]. Braga: Centros de Estudos em Educação e Psicologia da Universidade do Minho.

Cruz, J. F. (2006) Questionário de Auto-Apresentação no Exercício (QA-AE) - Versão para investigação [The Self- Presentation in Exercise Questionnaire]. Braga: Universidade do Minho.

Cruz, J. F., \& Gomes, A. R. (2007). Escala de Ansiedade no Desporto (EAD-2) - Versão para investigação [The Sport Anxiety Scale-2]. Braga: Universidade do Minho.

Cruz, J. F., \& Matos, M. F. (1997). Avaliação psicológica de factores e processos motivacionais no desporto: Características psicométricas de instrumentos para adolescentes [Evaluation of psychological factors and motivational processes in sport: Psychometric characteristics of instruments for adolescents]. In J. F. Cruz, \& A. R. Gomes, (Eds.), Psicologia aplicada ao desporto e à actividade física: Teoria, investigação e intervenção (pp. 325-337). Braga: Universidade do Minho-APPORT.

Davis, C., \& Cowles, M. (1989). A comparison of weight and diet concerns and personality factors among female athletes and non-athletes. Journal of Psychosomatic Research, 33, 527536. doi:10.1016/0022-3999(89)90060-3

De Bruin, Karin A. P., Oudejans, R. R. D., \& Bakker, F. C. (2007). Dieting and body image in aesthetic sports: A comparison of Dutch female gymnasts and nonaesthetic sport participants. Psychology of Sport and Exercise, 8, 507-520. doi:10.1016/j. psychsport.2006.10.002

DiBartolo, P. M., \& Shaffer, C. (2002). A comparison of female college athletes and nonathletes: Eating disorder symptomatology and psychological well-being. Journal of Sport \& Exercise Psychology, 24, 33-41. 
Duda, J. L. (1992). Motivation in sport settings: A goal perspective approach. In G. C. Roberts (Ed.), Motivation in sport and exercise (pp. 47-91). Champaign, IL: Human Kinetics.

Duda, J. L., \& Whitehead, J. (1998). Measurement of goal perspectives in the physical domain. In J. L. Duda (Ed.), Advances in sport and exercise psychology measurement (pp. 21-48). Morgatown, WV: Fitness Information Technology.

Fairburn, C. G., \& Beglin, S. J. (1994). The assessment of eating disorders: Interview or self-report questionnaire? International Journal of Eating Disorders, 16, 363-370. doi:10.1002/1098108X(199412)

Fairburn, C. G., \& Beglin, S. J. (2008). Eating disorder examination questionnaire (EDE-Q 6.0). In C. G. Fairburn (ed.), Cognitive Behavior Therapy and Eating Disorders (Appendix B). New York, NY: Guilford Press.

Fife-Schaw, C. (2006). Levels of measurement. In G. M. Breakwell, S. Hammond, C. Fife-Schaw, \& J. A. Smith (Eds.), Research methods in psychology (3rd ed) (pp. 50-63). London: Sage.

Fulkerson, J. A., Keel, P. K., Leon, G. R., \& Dorr, T. (1999). Eating-disordered behaviors and personality characteristics of high school athletes and non-athletes. International Journal of Eating Disorders, 26, 73-79. doi:10.1002/(SICI)1098108X(199907)

Gammage, K. L., Hall, C. R., Prapavessis, H., Maddison, R., Haase, A., \& Martin, K. A. (2004). Re-examination of the factor structure and composition of the Self- Presentation in Exercise Questionnaire (SPEQ). Journal of Applied Sport Psychology, 16, 82-91. doi: 10.1080/10413200490260071

Garner, D. M., Olmsted, M. P., \& Polivy, J. (1983). Development and validation of a multidimensional Eating Disorder Inventory for anorexia nervosa and bulimia. International Journal of Eating Disorders, 2, 15-34. doi:10.1002/1098108X(198321)

Ginis, K. A. M., \& Leary, M. R. (2004). Self-presentational processes in health-damaging behaviour. Journal of Applied Sport Psychology, 16, 59-74.doi:10.1080/10413200490260053

Gomes, A. R. (2007). Avaliação do Estado Físico e Desportivo (AEFD) - Versão para investigação [Sport Condition Questionnaire]. Braga: Universidade do Minho.

Haase, A. M., Prapavessis, H., \& Owens, R. G. (2002). Perfectionism, social physique anxiety and disordered eating: A comparison of male and female elite athletes. Psychology of Sport and Exercise, 3, 209-222. doi:10.1016/S14690292(01)00018-8

Hall, H. K, Kerr, A. W., Kozub, S. A., \& Finnie, S. B. (2007). Motivational antecedents of obligatory exercise: The influence of achievement goals and multidimensional perfectionism. Psychology of Sport and Exercise, 8, 297-316. doi:10.1016/j. psychsport.2006.04.007

Harris, M. B., \& Greco, D. (1990). Weight control and weight concern in competitive female gymnasts. Journal of Sport \& Exercise Psychology, 12, 427-433.

Hausemblas, H. A., Brewer, B. W., \& Van Raalte, J. L. (2004). Self-presentation and exercise. Journal of Applied Sport Psychology, 16, 3-18. doi:10.1080/10413200490260026
Hausenblas, H. A., \& McNally, K. D. (2004). Eating disorder prevalence and symptoms for track and field athletes and nonathletes. Journal of Applied Sport Psychology, 16, 274286. doi:10.1080/10413200490485630

Hausenblas, H. A., \& Symons, D. D. (2002). Exercise dependence: A systematic review. Psychology of Sport and Exercise, 3, 89123. doi:10.1016/S1469-0292(00)00015-7

Holm-Denoma, J. M, Scaringi, V., Gordon, K. H., Van Orden, K. A., \& Joiner Jr., T. E. (2009). Eating disorder symptoms among undergraduate varsity athletes, club athletes, independent exercisers, and nonexercisers. International Journal of Eating Disorders, 42, 47-53. doi:10.1002/eat.20560

Hulley, A. J., \& Hill, A. J. (2001). Eating disorders and health in elite women distance runners. International Journal of Eating Disorders, 30, 312-317. doi:10.1002/eat.1090

Johnson, C., Powers, P. S., \& Dick, R. (1999). Athletes and eating disorders: The National Collegiate Athletic Association Study. International Journal of Eating Disorders, 26, 179-188. doi:10.1002/(SICI)1098-108X(199909)

Johnson, M. D. (1994). Disordered eating in active and athletic women. Clinics in Sports Medicine, 13, 355-369.

Keel, P. K., Fulkerson, J. A., \& Leon, G. R. (1997). Disordered eating precursors in pre- and early adolescent girls and boys. Journal of Youth and Adolescence, 26, 203-216. doi:10.1023/A:1024504615742

Kerr, G., Berman, E., \& De Souza, M. (2006). Disordered eating in women's gymnastics: Perspectives of athletes, coaches, parents and judges. Journal of Applied Sport Psychology, 18, 28-43. doi:10.1080/10413200500471301

Killen, J. D., Taylor, C. B., Hayward, C., Haydel, K. F., Wilson, D. M., Hammer, L.,... Strachowski, D. (1996). Weight concerns influence the development of eating disorders: A 4-year prospective study. Journal of Consulting and Clinical Psychology, 64, 936-940. doi:10.1037/0022-006X.64.5.936

Klemchuk, H. P., Hutchinson, C. B., \& Frank, R. I. (1990). Body dissatisfaction and eating-related problems on the college campus: Usefulness of the Eating Disorder Inventory with a nonclinical population. Journal of Counseling Psychology, 37, 297-305. doi:10.1037/0022-0167.37.3.297

Lazarus, R. S. (1991). Emotion and adaptation. New York, NY: Oxford University Press.

Lazarus, R. S. (2000). How emotions influence performance in competitive sports. The Sport Psychologist, 14, 229-252.

Lazarus, R. S., \& Folkman, S. (1984). Stress, appraisal and coping. New York, NY: Springer.

Lipsey, Z., Barton, S. B., Hulley, A., \& Hill, A. J. (2006). “After a workouty" Beliefs about exercise, eating and appearance in female exercisers with and without eating disorder features. Psychology of Sport and Exercise, 7, 425-436. doi:10.1016/j. psychsport.2006.01.005

Luce, K. H., Crowther, J. H., \& Pole, M. (2008). Eating disorder examination questionnaire (EDE-Q): Norms for undergraduate women. International Journal of Eating Disorders, 41, 273276. doi:10.1002/eat.20504 
Machado, P. P. P. (2007). Questionário de alimentação: EDE-Q5.2 [Eating Questionnaire: EDE-Q5.2]. Braga: Centro de Investigação em Psicologia da Universidade do Minho.

Machado, P. P., Machado B. C., Gonçalves, S., \& Hoek, H. (2007). The prevalence of eating disorders not other wise specified. International Journal of Eating Disorders, 40, 212-217. doi:10.1002/eat.20358

Mantoanelli, G., Vitalle, M. S. S., \& Amancio, O.M.S. (2002). Amenorreia e osteoporose em adolescentes atletas [Amenorrhea and osteosporosis in adolescents athletes]. Revista de Nutrição, 15, 319-332. doi:10.1590/S141552732002000300008

Mond, J. M., Hay, P. J., Rodgers, B., \& Owen, C. (2006). Eating disorder examination questionnaire (EDE-Q): Norms for young adult women. Behaviour Research and Therapy, 44, 53-62. doi:10.1016/j.brat.2004.12.003

Muscat, A. C., \& Long, B. C. (2008). Critical comments about body shape and weight: Disordered eating of female athletes and sport participants. Journal of Applied Sport Psychology, 20, 1-24. doi:10.1080/10413200701784833

Nicholls, J. G. (1989). The competitive ethos and democratic education. Cambridge, MA: Harvard University Press.

Nunnally, J. C., \& Bernstein, I. H. (1994). Psychometric theory (3rd ed.). New York, NY: McGraw Hill.

Otis, C. L., Drinkwater, B., Johnson, M., Louks, A., \& Wilmore, J. (1997). American College of Sports Medicine position stand: The female athlete triad. Medicine \& Science in Sports \& Exercise, 29, 1-9. doi:10.1097/00005768-199705000-00037

Pasman, L., \& Thompson, K. J. (1988). Body image and eating disturbance in obligatory runners, obligatory weightlifters and sedentary individuals. International Journal of Eating Disorders, 7, 759-769. doi:10.1002/1098-108X(198811)

Petrie, T. A. (1996). Differences between male and female college lean sport athletes, nonlean sport athletes, and nonathletes on behavioral and psychological indices of eating disorders. Journal of Applied Sport Psychology, 8, 218-230. doi:10.1080/10413209608406478

Petrie, T. A., \& Greenleaf, C. (2007). Eating disorders in sport: From theory to research to intervention. In G. Tenenbaum, \& R. Eklund (Eds.), Handbook of sport psychology (3rd ed.) (pp. 352-378). Hoboken, NJ: Wiley.

Petrie, T. A., Greenleaf, C., Carter, J. E., \& Reel, J. J. (2007). Psychosocial correlates of disordered eating among male collegiate athletes. Journal of Clinical Sport Psychology, 1, 340-357.

Reel, J. J., SooHoo, S., Doetsch, H., Carter, J. E., \& Petrie, T. A. (2007). The female athlete triad: Is the triad a problem among division I female athletes? Journal of Clinical Sport Psychology, 1, 358-370.

Roberts, G. C. (2001). Understanding the dynamics of motivation in physical activity: The influence of achievement goals on motivational processes. In G. C. Roberts (Ed.), Advances in motivation in sport and exercise (pp. 1-51). Champaign, IL: Human Kinetics.
Rosen, L. W., McKeag, D. B., Hough, D. O., \& Curly, V. (1986). Pathogenic weight-control behaviour in female athletes. The Psysician and Sports Medicine, 14, 79-86.

Sanborn, C. F., Horea, M., Siemers, B. J., \& Dieringer, K. L. (2000). Disordered eating and female athlete triad. Clinical Sports Medicine, 19, 199-213. doi:10.1016/S0278-5919(05)70199-X

Sanford-Martens, T. C., Davidson, M. M., Yakushko, O. F., Martens, M. P., Hinton, P., \& Beck, N. (2005). Clinical and subclinical eating disorders: An examination of collegiate athletes. Journal of Applied Sport Psychology, 17, 79-86. doi:10.1080/10413200590907586

Sinton, M. M., \& Birch, L. L. (2005). Weight status and psychosocial factors predict the emergence of dieting in preadolescent girls. International Journal of Eating Disorders, 38, 346-354. doi:10.1002/eat.20176

Smith, R. E., Smoll, F. L., \& Schutz, R. W. (1990). Measurement and correlates of sport-specific cognitive and somatic trait anxiety: The Sport Anxiety Scale. Anxiety, Stress \& Coping, 2, 263-280. doi:10.1080/08917779008248733

Stice, E., Presnell, K., \& Spangler, D. (2002). Risk factors for binge eating onset: A prospective investigation. Health Psychology, 21, 131-138. doi:10.1037/0278-6133.21.2.131

Stoutjesdyk, D., \& Jevne, R. (1993). Eating disorders among high performance athletes. Journal of Youth and Adolescence, 22, 271-282. doi:10.1007/BF01537792

Sundgot-Borgen, J. (1993). Presence of eating disorders in elite female athletes. International Journal of Sport Nutrition, 3, 29-40.

Sundgot-Borgen, J. (1994a). Risk and trigger factors for the development of eating disorders in female elite athletes. Medicine \& Science in Sports \& Exercise, 26, 414-419. doi:10.1249/00005768-199404000-00003

Sundgot-Borgen, J. (1994b). Eating disorders in female athletes. Sports Medicine, 17, 176-188. doi:10.2165/00007256199417030-00004

Sundgot-Borgen, J. (1996). Eating disorders, energy intake, training volume, and menstrual function in high-level modern rhythmic gymnasts. International Journal of Sport Nutrition, 6, 100-109.

Szabo, A., Frenkl, R., \& Caputo, A. (1997). Relationships between addiction to running, commitment to running and deprivation from running: A study on the internet. In R. Seiler (Ed.), European Yearbook of Sport Psychology (Vol. 1, pp. 130-147). Augustin: FEPSAC.

Waldrop, J. (2005). Early identification and interventions for female athlete triad. Journal of Pediatric Health Care, 19, 213-220. doi:10.1016/j.pedhc.2005.02.008

West, R. V. (1998). The female athlete: The triad of disordered eating, amenorrhea and osteporosis. Sports Medicine, 26, 6371. doi:10.2165/00007256-199826020-00001

Received June 22, 2009

Revision received June 21, 2010

Accepted July 1, 2010 